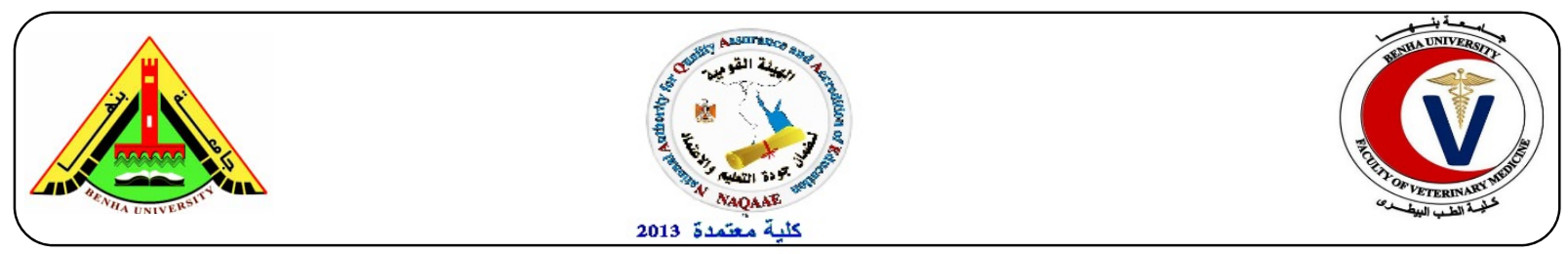

\title{
HACCP application during different processing stages of beef fillet with special references to corrective action.
}

\author{
Khalid Shappan Abukady', Fahim A. Shaltout ${ }^{1}$, Reham A. Amin ${ }^{1}$, Muhammad A. El-Shatter', and \\ Islam Ibrahim Sabike ${ }^{1}$ \\ ${ }^{1}$ Food hygiene Dept., Faculty of Veterinary Medicine, Benha University., ${ }^{2}$ Animal Health Research National Institute, \\ Food Control Dept., El-Dokki-Giza.
}

\section{A B S T R A C T}

Here, in this study HACCP program was applied for the production of beef fillet in an Egyptian hotel and the microbial load before and after application was compared. The aerobic plate count monitored before and after application of corrective action during different successive production stages of beef fillet in tested hotel to examine the frequency of contamination. The mean values of Aerobic plate count before application of corrective actions were 20.47 $\pm 7.01,71.33$ $\pm 15.27,680.0 \pm 385.53,528.67 \pm 255.39,24.33 \pm 8.09$, and $24.33 \pm 8.09$ (CFU/gm) for the examined frozen, thawed, formed, salted, cooked and served meat, respectively. After application of corrective action, the aerobic plate count declined to be $13.80 \pm 4.20,48.00 \pm 7.32,118.67 \pm 26.97,92.67 \pm 20.34,7.13 \pm 1.95$, and $<10$ in the examined frozen, thawed, formed, salted, cooked and served meat, respectively. The reduction percentages for the above examined samples were $32.5 \%, 32.7, \% 82.5 \%, 82.4 \%$, and $70.6 \%$ and $100 \%$, respectively. It is noticed that meat meals can be contaminated by several ways such as incorrect thawing, inadequate cleaning and sanitation for utensils or cross contamination after cooking resulting in higher contamination with microorganisms. No food borne pathogens of public health hazards detected during this study. This results shows the significant importance of HACCP program for prevention and control of pathogenic and spoilage microorganisms.

Keywords: HACCP, Aerobic plate count, beef fillet, Salmonella, E. coli.

(http://www.bvmj.bu.edu.eg)

(BVMJ-32(1): 138-144, 2017)

\section{INTRODUCTION}

In many countries, as people increasingly consume food prepared outside the home, growing numbers are potentially exposed to the risks of poor hygiene in commercial foodservice settings. While not all gastroenteritis is foodborne, and not all foodborne diseases cause gastroenteritis, food does represent an important vehicle for pathogens of substantial public health significance (WorldHealthOrganization, 2008). Food-borne pathogens are the leading cause of illness and death in developing countries costing billions of dollars in medical care and medical and social costs (Smith, 2005). In developing countries, rapid detection methods are always expensive and not available everywhere like developed countries, therefore, prevention of food borne diseases is always better and more economic than their control. Food safety concerns must cover the range of different food chains relevant to a certain food product or product group, including all relevant producers, manufacturing sites and food service establishments. HACCP, GMP and GHP are major components of the Safety management system in the food supply chain (Aruoma, 2006). The HACCP system is a preventive method of ensuring food safety. Its objectives are the identification of consumer safety hazards that can occur in the production line and the establishment of a control process to guarantee a safer product for the consumer. it is based on the identification of potential hazard to food safety and on measures aimed to prevent these hazards (Herrera, 2004; Vujacic, 2014). Each HACCP plan is specifically implemented for the processing plant and processing methods and requires a systematic collection of data on the incidence, elimination, prevention, and reduction of risks. (Osimani et al., 2013). Inadequate handling practices, inefficient cooking processes, cross-contamination, inadequate personal hygiene of food handlers, equipment and food-contact surfaces as well as inadequate holding time and temperature conditions are the constant problems of food processing (Valero et al, 2016)). Because meat and 
meat products are ideal media for bacterial Growth, so their safety and shelf life are very much dependent on the initial microbial contamination, good manufacturing practice, and storage temperature (Podolak et al., 1996). That is make the maintenance of good manufacturing practice is essential to maintain hygienic standard (Madden, 1994), and prevent microbial growth of meat, otherwise will lead to spoilage, economic losses, and reduction of meat quality. Therefore, it is expedient that great care should take during handling and the preparation of meat to avoid or reduce the level of microbial load and contamination. Thorough cooking processes and good hygiene practices could help to reduce the microbial load to harmless level (Antwi-Agyei and Maalekuu, 2014).

The Control measures are intended to prevent microorganisms from contaminating food and involve all hygienic production measures (Sinell, 1995). Here, the objective of the present study was to apply HACCP system in a hotel to ensure food safety for meat preparations. Therefore, bacteriological quality of meat preparations in a hotel before and after HACCP application was evaluated.

\section{MATERIALS AND METHODS}

\subsection{Collection of samples: (Andrews, 1992).}

A grand total of ninety random samples of frozen beef fillet were taken from receiving area of Egyptian touristic hotel in sterile plastic bags. Then these meat samples are frozen, thawed, formed, salted, cooked and served (15 of each)

\subsection{Preparation of samples (Roberts et al., 1996):}

Twenty-five grams of the examined samples were transferred to a sterile polyethylene bag, and $225 \mathrm{ml}$ of $0.1 \%$ sterile buffered peptone water were aseptically added to the content of the bag. Each sample was then homogenized in a blender at $2000 \mathrm{rpm}$ for 1-2 minutes to provide a homogenate of $1 / 10$ dilution. One $\mathrm{ml}$ from the original dilution was transferred with sterile pipette to another sterile test tube containing $9 \mathrm{ml}$ of sterile buffered peptone water $0.1 \%$ and mixed well to make the next dilution, from which further decimal serial dilutions were prepared.

\subsection{Enumeration of total bacterial count (cfu/g) (Andrews, 1992):}

One $\mathrm{ml}$ from each of the previously prepared serial dilution was poured into two separate sterile Petri dishes, using Pour plate method, to which approximately $15 \mathrm{ml}$ of sterile melted and tempered plate count agar $\left(45^{\circ} \mathrm{C}\right)$ were poured.
After thorough mixing, the inoculated and control plates were allowed to solidify before being incubated in an inverted position at $37^{\circ} \mathrm{C}$ for $48 \mathrm{hrs}$. Total bacterial count (TBC) per gram was calculated on plates containing 30-300 colonies and each count was recorded separately.

\subsection{Identification of hazard and suggestion of suitable corrective action}

Upon visual observations and results of laboratory tests, meat contact surfaces hygiene, personnel hygiene, cooking, and serving were determined as critical control points in the processing line, and the suggested corrective actions were established.

\subsection{Application of suggested corrective actions for each CCP in beef fillet line of production:}

\subsubsection{Processing steps}

Before production of the product the workers were trained for the correct production steps of the beef fillet product concerning the critical temperature of production, cooking or storage. The workers were also trained about the correct way to store non-meat ingredients.

\subsubsection{Personal hygiene:}

Before application of the corrective action plans with sufficient times, workers were trained about personal hygiene principals and educated about how to do their job in such way to minimize contamination of both the products and the processing plants. Workers were also informed about the aim of washing, cleaning and disinfection; and were also trained to use the protective wears and disposable gloves effectively.

\subsubsection{Cleaning and disinfection programs}

\subsubsection{Hand disinfection:}

The Iodocare (Kleencare) hand disinfectant was used in a $10 \% \mathrm{v} / \mathrm{v}$ solution $(100 \mathrm{ml}$ iodocare diluted to 1 -liter water). The workers were educated to wash their hands correctly with suitable hand soap and hot water before dipping their hands in the disinfectant solution. The working solution should be replaced with fresh one when the iodine been discharged (The amber/ Yellow color is lost)

\subsubsection{Surfaces, plates and machines disinfection:}

The machines and surfaces washed by soap and hot water then they sprayed with the disinfectant material (iso propanol with emulsifier \& dodacyl di methyl ammonium chloride) this compound called commercially P.T.S.

\subsubsection{Cooking process}


Grilled meat at $200^{\circ} \mathrm{c}$ for about 6 minutes then boiled with sauce for another 15 minutes to obtain inside brownish color and $71.1{ }^{\circ} \mathrm{c}$ inside temperature (Safe cooking temp) or grilled the meat at $180-200^{\circ} \mathrm{c}$ then transported it to preheated oven at $218{ }^{\circ} \mathrm{c}$ and it take about 40 minutes to obtain well done cooked meat and to ensure that you obtain the well done cooked meat the food thermometer should be inserted in the innermost portion of the meat till obtain the required temperature $71.1^{\circ} \mathrm{c}$.

\subsubsection{Serving}

The cooked beef fillet removed by using fork to clean and sanitized dishes and served directly and food touched directly by hands without disposable gloves, fork, napkin or any hygienic insulator must be condemned or reheated directly and cooked food must be eat directly or served in hot cabin at $65^{\circ} \mathrm{C}$ not more than $6 \mathrm{hrs}$ or served at $5^{\circ} \mathrm{C}$ or below then reheated to above than $70{ }^{\circ} \mathrm{C}$ then consumed directly but this study is implicated in cook serve system in which the food directly consumed after cooking by 10 minutes Maximally

\subsection{Visual monitoring and laboratory monitoring to evaluate the effect of suggested corrective action and to detect any deviation.}

Visual observation for all processing steps is very necessary to control any deviation during the hall operation processing line and any deviation must be controlled and corrected if the corrective action can be applied and bacteriological examination for each corrected CCP must be applied again to assure the efficacy of control and determine if there is any CCP that not being under control. Moreover, comparisons between the bacterial load of different CCP in the production line before and after application of HACCP were done.

\section{RESULTS}

Results presented in Table (1) revealed that, the mean values of APC ( $\mathrm{cfu} / \mathrm{g}$ ) of the randomly taken samples of frozen, thawed, formed, salted, cooked and served meat meals from a hotel were $20.47 \pm$ 7.01 for the frozen meat, $71.33 \pm 15.27$ for thawed meat, $680.0 \pm 385.53$ for formed meat, 528.67 \pm 255.39 for salted meat, $24.33 \pm 8.09$ for cooked meat and $24.33 \pm 8.09$ for served meat respectively. Table (2) shows that, the mean values of APC $(\mathrm{cfu} / \mathrm{g})$ of the randomly taken samples of frozen, thawed, formed, salted, cooked and served meat meals after the application of the corrective actions were $13.80 \pm 4.20,48.00 \pm 7.32,118.67 \pm 26.97$ $92.67 \pm 20.34,7.13 \pm 1.95$, and $<10$ respectively

Table (1) Aerobic bacterial count (CFU/gm) of meat sampled during different stages of beef fillet manufacturing before application of corrective action:

\begin{tabular}{lccc}
\hline Product & Minimum & Maximum & Mean \pm SE \\
\hline Frozen & $<10$ & 100 & $20.47 \pm 7.01$ \\
Thawed & 20 & 200 & $71.33 \pm 15.27$ \\
Formed & 50 & 6000 & $680.0 \pm 385.53$ \\
Salted & 50 & 4000 & $528.67 \pm 255.39$ \\
Cooked & $<10$ & 120 & $24.33 \pm 8.09$ \\
Served & $<10$ & 140 & $34.47 \pm 9.41$ \\
\hline
\end{tabular}

Table (2) Aerobic bacterial count (CFU/gm) of meat before and after application of corrective action with deceleration of the reduction percentage (sampled during different stages of beef fillet manufacturing):

\begin{tabular}{lccccccc}
\hline \multirow{2}{*}{ Products } & \multicolumn{2}{c}{ Min. } & \multicolumn{2}{c}{ Max. } & \multicolumn{2}{c}{ Mean \pm SE } & \multirow{2}{*}{ Reduction \% } \\
& Before & after & Before & After & Before & After & \\
\hline Frozen & $<10$ & $<10$ & 100 & 60 & $20.47 \pm 7.01$ & $13.80 \pm 4.20$ & $32.5 \%$ \\
Thawed & 20 & 20 & 200 & 120 & $71.33 \pm 15.27$ & $48.00 \pm 7.32$ & $32.7 \%$ \\
Formed & 50 & 20 & 6000 & 400 & $680.0 \pm 385.53$ & $118.67 \pm 26.97$ & $82.5 \%$ \\
Salted & 50 & 20 & 4000 & 300 & $528.67 \pm 255.39$ & $92.67 \pm 20.34$ & $82.4 \%$ \\
Cooked & $<10$ & $<10$ & 120 & 20 & $24.33 \pm 8.09$ & $7.13 \pm 1.95$ & $70.6 \%$ \\
Served & $<10$ & $<10$ & 140 & $<10$ & $34.47 \pm 9.41$ & $<10$ & $100 \%$ \\
\hline
\end{tabular}


HACCP application during different processing stages of beef fillet with special references to corrective action.

Table (3): Incidences of isolated Enterobacteriaceae (meat samples) $(N=53)$

\begin{tabular}{lll}
\hline No of isolate & Isolate & Percentage \% \\
\hline 4 & Citrobacter diversus & 7.547 \\
7 & Citrobacter freundii & 13.207 \\
4 & Enterobacter aerogenes & 7.547 \\
2 & Enterobacter agglomerans & 3.77 \\
7 & Enterobacter cloacae & 13.207 \\
3 & Enterobacter hafniae & 5.66 \\
4 & Klebsiella azaenae & 7.547 \\
4 & Klebsiella pneumoniae & 7.547 \\
4 & Proteus mirabilis & 7.547 \\
5 & Proteus rettgeri & 9.43 \\
8 & Proteus vulgaris & 15.09 \\
1 & Serratia liquefaciens & 1.886 \\
\hline
\end{tabular}

Table (4) Serological identification of E. coli samples of meat (frozen, thawed, formed, salted, cooked and served).

\begin{tabular}{lllll}
\hline $\begin{array}{l}\text { Identified } \\
\text { bacterium }\end{array}$ & Sero diagnosis & Strain characterization & No & \% \\
\hline E.coli & O55:K59(B5) & EPEC & 1 & $10 \%$ \\
E.coli & O111:K58(B9) & EHEC & 1 & $10 \%$ \\
E.coli & O128:K67(B12) & ETEC & 1 & $10 \%$ \\
----------- & Un typed & ---------- & 7 & $70 \%$ \\
\hline
\end{tabular}

Figure (1): shows differences in Aerobic bacterial count before and after application of corrective action in different meat products.

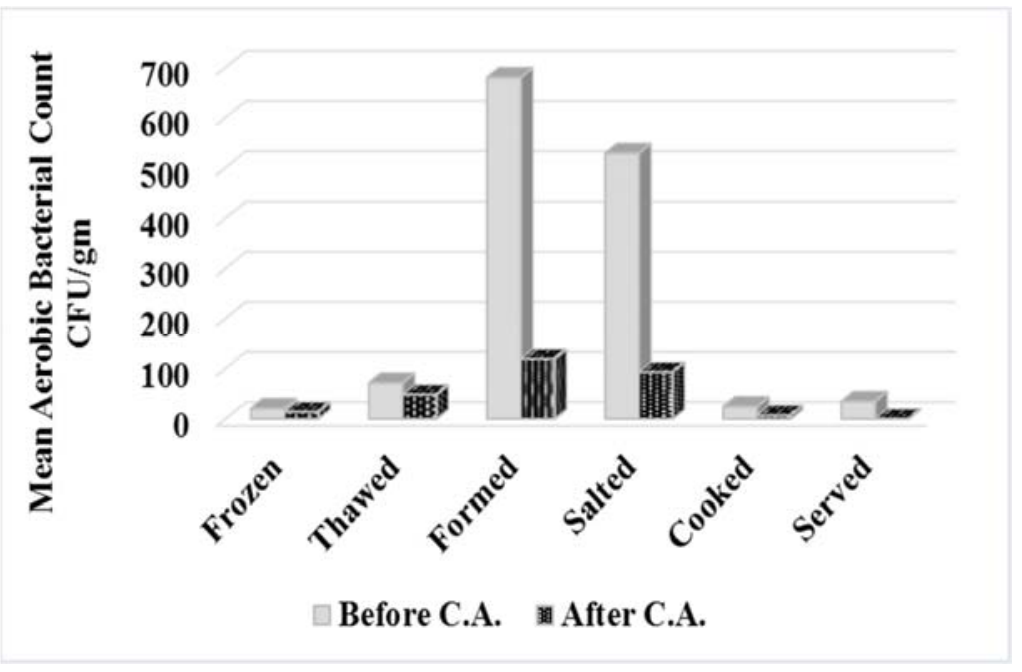


Figure (2): Reduction percentages of Aerobic bacterial count in different meat products after application of corrective action.

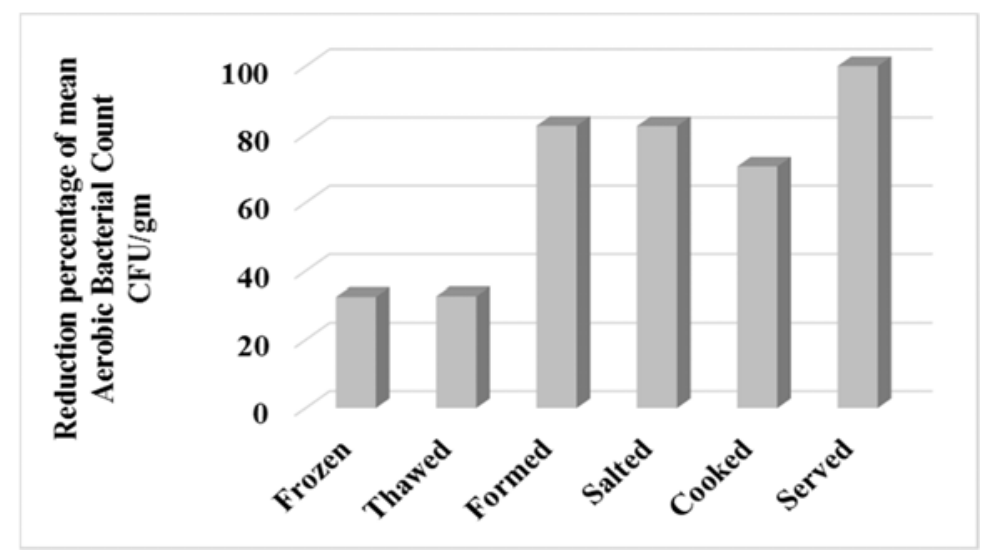

in comparison with the results of the same samples before application of corrective actions. This is obviously noticed on figure (1). Also, figure (2) and Table (2) shows the reduction ppercent of the APC that was $32.5 \%, 32.7, \% 82.5 \%, 82.4 \%$, and $70.6 \%$ and $100 \%$ respectively. This result shows the positive effect of the corrective actions on decreasing the microbial count of meat during different processing steps. Table (3) show the percent of isolates of Enterobacteriaceae from a total No. of 53 isolates the Proteus vulgaris were [8(15.09\%)], Enterobacter cloacae [7(13.2\%)], Klebsiella pneumoniae [4(7.5\%)], Citrobacter freundii [7(13.2\%)], Proteus rettgeri [5(9.43\%)], Citrobacter diversus [4(7.5\%)], Enterobacter aerogenes [4(7.5\%)], Proteus mirabilis [4(7.5\%)], Klebsiella azaenae [4(7.5\%)], Serratia liquefaciens $\quad[1(1.88 \%)]$, Enterobacter agglomerans $[2(3.77 \%)]$ and $[3(5.66 \%)]$ Enterobacter hafniae. Table (4) shows the percent of $E$. coli isolated from the coliform samples of meat the result was per percent from a total (10) samples and it was10 \% E. coli O55:K59(B5) EPEC), 10\% E. coli O111:K58(B9) EHEC and 10\% E. coli O128:K67(B12) ETEC and the other $70 \%$ were un typed

\section{DISCUSSION}

Consumer's priority to obtain safe food, mandates food serving establishments to apply programs like Good Manufacturing practices (GMP), Good Hygienic Practices (GHP), and HACCP to prevent and control foodborne pathogens. No doubt that this programs achieved their aim when they properly applied, therefore most food safety agencies recommended their application. When food is perishable as meat another issue will be control of spoilage. Here in this study different steps of beef fillet production (frozen, thawed, formed, salted, cooked and served meat meals) in a hotel, have been bacteriologically monitored using total aerobic and coliform counts before and after application of corrective actions. Results of aerobic bacterial count $(\mathrm{cfu} / \mathrm{g})$ of the examined samples showed in tables $(1 \& 2)$ were somewhat like those of Fliss et al. (1991), and too closely similar to Emam et al. (2013) who recorded that the total APC of chicken pane were $2 \times 10^{1}$.whereas Samaha et al. (2016) reported results higher than the results of this study and the mean value of his results were more than permissible limits. Similarly, Hassan et al. (2015) reported higher APC results on the same item (beef fillet in hotels). The Aerobic Colony Count (ACC), also known as the Total Viable Count or Standard Plate Count, is an indicator of quality and remaining shelf-life of the food in question, and thus highlight potential problems of storage and handling since production, not safety, and cannot directly contribute towards a safety assessment of ready-to-eat food. High counts may suggest quality issues and possible poor temperature control and these should be investigated (HealthProtectionAgency, 2009).

The further processing and/or handling of meat, meat preparations, meat-handling work surfaces and meat products provides an opportunity for any dangerous bacteria to be spread throughout the product and for new bacteria to be introduced from the environment which noticed, with the higher number of total APC, during formed and salted stages

Enterobacteriaceae bacteria (EB) are commonly found in meat products such as beef. Some serotypes of Enterobacteriaceae that isolated in (Table 3) are isolated by Tassew et al. (2010). While the percent of serologically identified $E$. 
Coli on Table (4) is nearly similar to the percentage of isolated serotypes isolated by Gallien et al. (1999) who recorded that the occurrence of nonO157 (STEC) in meat from Europe has ranged from $1.8 \%$ to $19.0 \%$. While Samaha et al. (2016) recorded incidence of pathogenic E. coli more than my rates.

From analysis of the data obtained from visual observation and microbiological examinations of the meat meal throughout its processing line it can clearly estimate that cooking is the first critical control points in the preparation line where meat was thermally treated by grilling of meat at $200{ }^{\circ} \mathrm{c}$ for about 10 minutes then boiled with sauce for another 10 minutes to obtain inside brownish color and $71.1^{\circ} \mathrm{c}$ inside temperature, which was sufficient to eliminate all the investigated bacterial group with highly reductions of the APC and so serving is a critical control point as the food hazards must be controlled at this point to prevent occurrence of food-borne outbreak and serving can also decrease the microbial count to nonhazardous level as the food stand for a few minutes under 100 ${ }^{\circ} \mathrm{C}$ on the cook serve systems. Appendices (1998) established that complete and accurate identification of CCPs is fundamental to control food safety. Table (3) show the percent of the most important bacteria that isolated from various processing stages. Of a total number of 53 isolates the Proteus vulgaris were 8(15.09\%), Enterobacter cloacae 7(13.2\%), Klebsiella pneumoniae 4(7.5\%), Citrobacter freundii 7(13.2\%), Proteus rettgeri 5(9.43\%), Citrobacter diversus 4(7.5\%), Enterobacter aerogenes 4(7.5\%), Proteus mirabilis 4(7.5\%), Klebsiella azaenae 4(7.5\%), Serratia liquefaciens 1(1.88\%), Enterobacter agglomerans $2(3.77 \%)$ and $3(5.66 \%)$ Enterobacter hafniae. Similarly, some of these serotypes isolated by Tassew et al. (2010) and El-Gendy et al. (2014). The occurrence of these spp. in the meat and swab samples can obviously be attributed to unhygienic food processing, inadequate sanitary conditions and poor general hygiene (Gwida et al., 2014).

The Enterobacteriaceae family is a group of bacteria that is used to assess the general hygiene status of a food product. This group includes species that originate from the intestinal tract of animals and humans, as well as plants and the environment. Indicator organisms are useful in the assessment of food product safety because they tend to be present in higher numbers than most pathogens and are relatively quick and easy to identify Escherichia coli belongs to the Enterobacteriaceae family and is used as a fecal indicator to assess the hygiene status of a food product. Table (4) shows the percent of E. coli isolated from the coliform samples of meat. the result was in percent from a total (10) samples and it was $10 \%$ E. coli O55:K59(B5) EPEC), 10\% E. coli O111:K58(B9) EHEC and 10\% E. coli O128:K67(B12) ETEC and the other $70 \%$ were un typed. This result is nearly similar to Gallien et al. (1999) who recorded that the occurrence of nonO157 (STEC) in meat from Europe has ranged from $1.8 \%$ to $19.0 \%$. Samaha et al. (2016) recorded incidence of pathogenic E. coli more than our study.

Previous studies reported the ability of foodborne disease microorganisms to become disseminated from infected foods to hand and food contact surfaces in the domestic kitchen (Gorman et al., 2002). Different corrective actions were applied to each step in the preparation line to minimize the microbial population and save guard the consumer health. The corrective actions include providing the receiving area with fabric curtain with cleaning and disinfection of conveyers. In addition to maintain the temperature of the truck transporting the meat at $-18^{\circ} \mathrm{C}$. These measures could lower the APC. Thawing of meat at $10^{\circ} \mathrm{C}$ till complete thawing with frequent collection of drip, as well as cleaning and disinfecting of these rooms and tracks and pallets result in significant reduction of the APC. Also, cooking of food with GHP could help reduce the microbial load to harmless level (Antwi-Agyei and Maalekuu, 2014) .

Conclusively, significant reduction in Aerobic plate counts and Enterobacteriaceae counts after application of corrective actions was noticed, which reflect the great importance of mandating HACCP systems in Egyptian food serving establishments. Consequently, ensuring introduction of safe food and lowering risks of foodborne pathogens.

\section{REFERENCES}

Andrews, W., 1992. Manual of food quality control. 4. Rev. 1. Microbiological analysis. Food and Drug Administration. FAO food and nutrition paper 14, 1-338.

Antwi-Agyei, P., Maalekuu, B., 2014. Determination of microbial contamination in meat and fish products sold in the Kumasi metropolis (A Case Study of Kumasi central market and the Bantama market). Merit Research Journal of Agricultural Science and Soil Sciences 2, 38-46.

Appendices, V., 1998. Hazard analysis and critical control point principles and 
application guidelines. Journal of Food Protection 61, 1246-1259.

Aruoma, O.I., 2006. The impact of food regulation on the food supply chain. Toxicology 221, 119-127.

El-Gendy, N.M., Ibrahim, H.A., Al-Shabasy, N.A., Samaha, I.A., 2014. Enterobacteriaceae In Beef Products (Luncheon, Pasterma, Frankfurter and Minced meat) from Alexandria Retail Outlets. Alexandria Journal of Veterinary Sciences 41, 80-86.

Emam, A., Ashour, E., El-Fattah, M., 2013. Microbiological hazards during preparation of some ready to eat meals and their control measures. World Journal of Dairy \& Food Sciences 8, 131-139.

Fliss, I., Simard, R., Ettrikf, A., 1991. Microbiological quality of different fresh meat species in Tunisian slaughterhouses and markets. Journal of Food Protection ${ }^{\circledR}$ 54, 773-777.

Gallien, P., Much, C., PERLBERG, K.-W., Protz, D., 1999. Subtypisierung von stxGenen in Shigatoxin-produzierenden Escherichia coli (STEC): Vorkommen in rohen Lebensmitteln und Korrelationen $\mathrm{zu}$ anderen Faktoren. Fleischwirtschaft 79, 99-103.

Gorman, R., Bloomfield, S., Adley, C.C., 2002. A study of cross-contamination of food-borne pathogens in the domestic kitchen in the Republic of Ireland. International Journal of Food Microbiology 76, 143-150.

Gwida, M., Hotzel, H., Geue, L., Tomaso, H., 2014. Occurrence of Enterobacteriaceae in Raw Meat and in Human Samples from Egyptian Retail Sellers. International Scholarly Research Notices 2014, 6.

Hassan, M., Amin, R.A., El-Salhy, M., 2015. Bacteriological and Chemical Evaluation of Meat Meals in Some Egyptian Hotels.

HealthProtectionAgency, 2009. Guidelines for assessing the microbiological safety of ready-to-eat foods placed on the market. Health Protection Agency, 2009: 17-26.
Herrera, A.G., 2004. The hazard analysis and critical control point system in food safety. Public Health Microbiology: Methods and Protocols, 235-280.

Madden, R.H., 1994. Microbial hazards in animal products. Proceedings of the Nutrition Society 53, 309-316.

Osimani, A., Aquilanti, L., Tavoletti, S., Clementi, F., 2013. Evaluation of the HACCP system in a university canteen: Microbiological monitoring and internal auditing as verification tools. International journal of environmental research and public health 10, 15721585.

Podolak, R., Zayas, J., Kastner, C., Fung, D., 1996. Reduction of bacterial populations on vacuum-packaged ground beef patties with fumaric and lactic acids. Journal of food protection 59, 1037-1040.

Roberts, T., Tompkin, R., Baird-Parker, A., 1996. Microorganisms in foods 5: Microbiological specifications of food pathogens. Chapman \& Hall.

Samaha, I.A., Nossair, M.A., Kassem, A.A., 2016. Microbial Evaluation of Heat Treated Meat Products. AJVS 49, 153159.

Sinell, H.-J., 1995. Control of food-borne infections and intoxications. International journal of food microbiology 25, 209-217.

Smith, J.L., 2005. Foodborne pathogens: microbiology and molecular biology. Horizon Scientific Press.

Tassew, H., Abdissa, A., Beyene, G., GebreSelassie, S., 2010. Microbial flora and food borne pathogens on minced meat and their susceptibility to antimicrobial agents. Ethiopian journal of health sciences 20.

Vujacic, V., 2014. Importance of Application of Hazard Analysis and Critical Control Point (Haccp) in Montenegro Tourism. Researchers World 5, 8.

WorldHealthOrganization, 2008. Foodborne disease outbreaks: guidelines for investigation and control. World Health Organization. 